\title{
"Correlating the Cold Filter Plugging Point to Concentration and Melting Properties of Fatty Acid Methyl Ester (Biodiesel) Admixtures"
}

\section{Supporting Information}

\section{Cold Filter Plugging Point (CFPP) Correlation Models from the Literature}

Twenty-six (26) mathematical models were found in the scientific literature for calculating the CFPP of biodiesel based on fatty acid methyl ester (FAME) compositions. Sources and reported results for these models are in Table S1 below. Models numbered 1-19 are correlated to total saturated-FAME ( $\Sigma$ SFAME) concentration, the concentrations of one or combinations of individual SFAME or the total unsaturated-FAME ( UFFAME) concentration. ${ }^{1-10}$ Models 20-22 are linear correlations with respect to three types of long-chain saturation factors (LCSF) which are weighted average concentrations of SFAME. ${ }^{11,12}$ The first two factors were reported by Ramos et al. ${ }^{12}$ where the assigned weights are 1) LCSF[A]-Ramos: melting point (MP; $\left.{ }^{\circ} \mathrm{C}\right)$ of pure SFAME species starting with methyl stearate (MeC18); and 2) LCSF[B]-Ramos: 0.1, 0.5, $1.0,1.5$ and 2.0 for methyl palmitate, stearate, arachidate, behenate and lignocerate $(\mathrm{MeC} 16$, $\mathrm{MeC} 18, \mathrm{MeC} 20, \mathrm{MeC} 22$ and $\mathrm{MeC} 24)$, respectively. The third factor, LCSF-Wang ${ }^{11}$, was similar to LCSF[A]-Ramos except that methyl myristate (MeC14) and MeC16 were also counted. The remaining four models were partially correlated to structural factors for the FAME mixtures. Model 23 was correlated with respect to the average FAME chain length including the headgroup $\left(N_{\mathrm{C}}\right.$, mole basis) and $\Sigma$ UFAME in mol\% ${ }^{13}$ Model 24 was correlated with respect to the iodine value (IV; $\mathrm{g} \mathrm{I}_{2} \mathrm{~g}^{-1}$ oil) of the FAME mixture. ${ }^{8}$ Models 25 and 26 were correlated with respect to the average FAME chain length excluding the headgroup (LC; mass basis), degree of unsaturation (DU; mass basis) and kinematic viscosity $(v)$ at $40{ }^{\circ} \mathrm{C} .{ }^{14}$

Table S1. Correlations for Calculating the Cold Filter Plugging Point (CFPP) of Biodiesel. ${ }^{a}$ Equations defined by number below.

\begin{tabular}{|c|c|c|c|c|c|}
\hline No. & Name $^{b}$ & Variables $^{c}$ & $R^{2}$ & $\sigma_{\mathrm{y}}$ & Notes \\
\hline 1 & Echim & $\begin{array}{l}\Sigma \text { SFAME; mass } \% \\
\Sigma \text { SFAME; mass } \%\end{array}$ & $\begin{array}{l}0.9271(a) \\
0.9378(b)\end{array}$ & $\begin{array}{l}\text { NR } \\
\text { NR }\end{array}$ & $\begin{array}{l}\text { Two parts: (a) admixtures; (b) neat } \\
\text { (unblended) biodiesel }\end{array}$ \\
\hline 2 & Gonzalez & $\Sigma$ SFAME; mass $\%$ & 0.9519 & NR & $\Sigma \mathrm{SFAME}=14-27 \%$ \\
\hline 3 & Jeong 1 & $\Sigma$ SFAME; mass $\%$ & 0.917 & NR & \\
\hline 4 & Moser 1 & $\Sigma$ SFAME; mass $\%$ & 0.861 & NR & $\Sigma \mathrm{SFAME}=7-48 \%$ \\
\hline 5 & Moser $2^{d}$ & $\Sigma$ SFAME; mass $\%$ & 0.978 & 0.85 & $\Sigma$ SFAME $=14-27 \%$ \\
\hline 6 & Chen & $y_{\mathrm{C} 16}, y_{\text {Eleo-C18}} ;$ mass fracs & NR & NR & $y_{\mathrm{C} 16}=0-0.455$ \\
\hline 7 & Jeong 2 & $Y_{\mathrm{C} 16} ;$ mass $\%$ & 0.845 & NR & \\
\hline 8 & Sarin 1 & $Y_{\mathrm{C} 16} ; \operatorname{mass} \%$ & 0.863 & 1.8 & $Y_{\mathrm{C} 16}=0-45 \%$ \\
\hline 9 & Serrano 1 & $\begin{array}{l}\Sigma \text { SFAME(C4-C14), } \\
\Sigma \text { SFAMEC16-C24), } \\
\text { ¿UFAME; mass\% }\end{array}$ & 0.93 & $1.8^{e}$ & $\begin{array}{l}\Sigma \text { SFAME }(\mathrm{C} 4-\mathrm{C} 14)=0-81.1 \% \\
\Sigma \text { SFAME }(\mathrm{C} 16-\mathrm{C} 24)=7.4-44.4 \% \\
\Sigma \mathrm{UFAME} \leq 92.2\end{array}$ \\
\hline 10 & Serrano 2 & ¿SFAME (C16-C24); mass\% & 0.95 & $1.6^{e}$ & $\Sigma \mathrm{SFAME}(\mathrm{C} 16-\mathrm{C} 24)=7.4-44.4 \%$ \\
\hline 11 & Yuan 1 & $\begin{array}{l}Y_{\mathrm{i}}, i=\mathrm{C} 14-\mathrm{C} 20 \text { (SFAME); } \\
\text { mass } \%\end{array}$ & 0.866 & 2.23 & $F=483$ \\
\hline 12 & Yuan 2 & $\begin{array}{l}Y_{\mathrm{i}}, i=\mathrm{C} 14-\mathrm{C} 20 \text { (SFAME); } \\
\text { mass } \%\end{array}$ & 0.929 & 1.53 & $\begin{array}{l}\text { Admixtures where MAG concentration } \\
\text { is known; } F=545\end{array}$ \\
\hline 13 & Yuan 3 & $\begin{array}{l}Y_{\mathrm{i}}, i=\mathrm{C} 16-\mathrm{C} 20(\mathrm{SFAME}) \\
\mathrm{mass} \%\end{array}$ & 0.871 & 2.14 & $\begin{array}{l}\text { Admixtures with long-chain (C14+) } \\
\text { FAME: } F=583\end{array}$ \\
\hline
\end{tabular}




\begin{tabular}{|c|c|c|c|c|c|}
\hline 14 & Yuan 4 & $\begin{array}{l}Y_{\mathrm{i}}, i=\mathrm{C} 16-\mathrm{C} 18(\mathrm{SFAME}) \\
\text { mass } \%\end{array}$ & 0.937 & 1.75 & $\begin{array}{l}\text { Admixtures with medium-chain (C10- } \\
\text { C12) FAME; } F=283\end{array}$ \\
\hline 15 & Yuan 5 & $\begin{array}{l}Y_{\mathrm{i}}, i=\mathrm{C} 16-\mathrm{C} 18 \text { (SFAME) } \\
\text { mass } \%\end{array}$ & 0.904 & 1.92 & $\begin{array}{l}\text { Admixtures with RME (low-erucic); } \\
F=42\end{array}$ \\
\hline 16 & Jurac 1 & $\Sigma$ UFAME; mass $\%$ & 0.9789 & NR & RME/UCOME admixture \#1 \\
\hline 17 & Jurac 2 & $\Sigma$ ¿UFAME; mass \% & 0.9948 & NR & RME/UCOME admixture \#2 \\
\hline 18 & Park & $\Sigma$ UFAME; mass $\%$ & NR & NR & $\begin{array}{l}\text { Two equations depending on } \\
\Sigma \text { UFAME range }\end{array}$ \\
\hline 19 & Sarin 2 & $\Sigma$ UFAME; mass $\%$ & 0.872 & 1.8 & $\Sigma$ UFAME $=0-84 \%$ \\
\hline 20 & Ramos 1 & LCSF[A]-Ramos & 0.8943 & NR & \\
\hline 21 & Ramos 2 & LCSF[B]-Ramos & 0.966 & NR & \\
\hline 22 & Wang & LCSF-Wang & 0.9092 & NR & \\
\hline 23 & $\mathrm{Su}$ & Nc; $\Sigma$ UFAME; mol\% & NR & $2.31^{f}$ & \\
\hline 24 & Moser 3 & IV & 0.674 & NR & $\mathrm{IV}=54-110$ \\
\hline 25 & Pinzi 1 & LC, DU & 0.43 & 0.39 & \\
\hline 26 & Pinzi 2 & $\mathrm{LC}, \mathrm{DU}, v$ & 0.944 & 0.19 & \\
\hline
\end{tabular}

${ }^{a} R^{2}=$ Adjusted correlation coefficient; $\sigma_{\mathrm{y}}=$ standard error of the $y$-estimate; FAME $=$ fatty acid methyl ester; $\mathrm{NR}=$ not reported; RME = rapeseed oil-FAME; UCOME = used cooking oil-FAME; $F=$ variance ratio (residuals/model). ${ }^{b}$ Sources: References 1-14.

'Independent variables: $\Sigma$ UFAME $=$ total unsaturated-FAME concentration; LCSF $=$ long-chain saturation factors (LCSF[A]-Ramos, LCSF[B]-Ramos and LCSF-Wang) defined in equations below; $Y_{\mathrm{i}}=$ mass $\%$ and $y_{\mathrm{i}}=$ mass fraction where $i=$ FAME tailgroup chain-length $\left(\mathrm{C}_{\mathrm{n}}\right) ; N_{\mathrm{C}}=$ average chain length including headgroup (mole basis); $\Sigma$ SFAME $=$ total saturated-FAME concentration; $Y_{\text {Eleo-C18 }}=$ mass $\%$ methyl eleostearate $(\mathrm{C} 18: 3-9,11,13) ; \mathrm{IV}=$ iodine value $\left(\mathrm{g} \mathrm{I}_{2} \mathrm{~g}^{-1}\right) ; \mathrm{LC}=$ average chain length excluding headgroup (mass basis); DU = degree of unsaturation (mass basis); $v$.

${ }^{d}$ Model equation inferred from data reported in Moser, 2008. ${ }^{8}$

${ }^{e}$ Root-mean-squared deviation (RMSD).

${ }^{f}$ Average relative deviation (ARD).

Equations for the models shown in Table S1 are given below. ${ }^{1-14}$ Unless noted otherwise, CFPP is in ${ }^{\circ} \mathrm{C}$ :

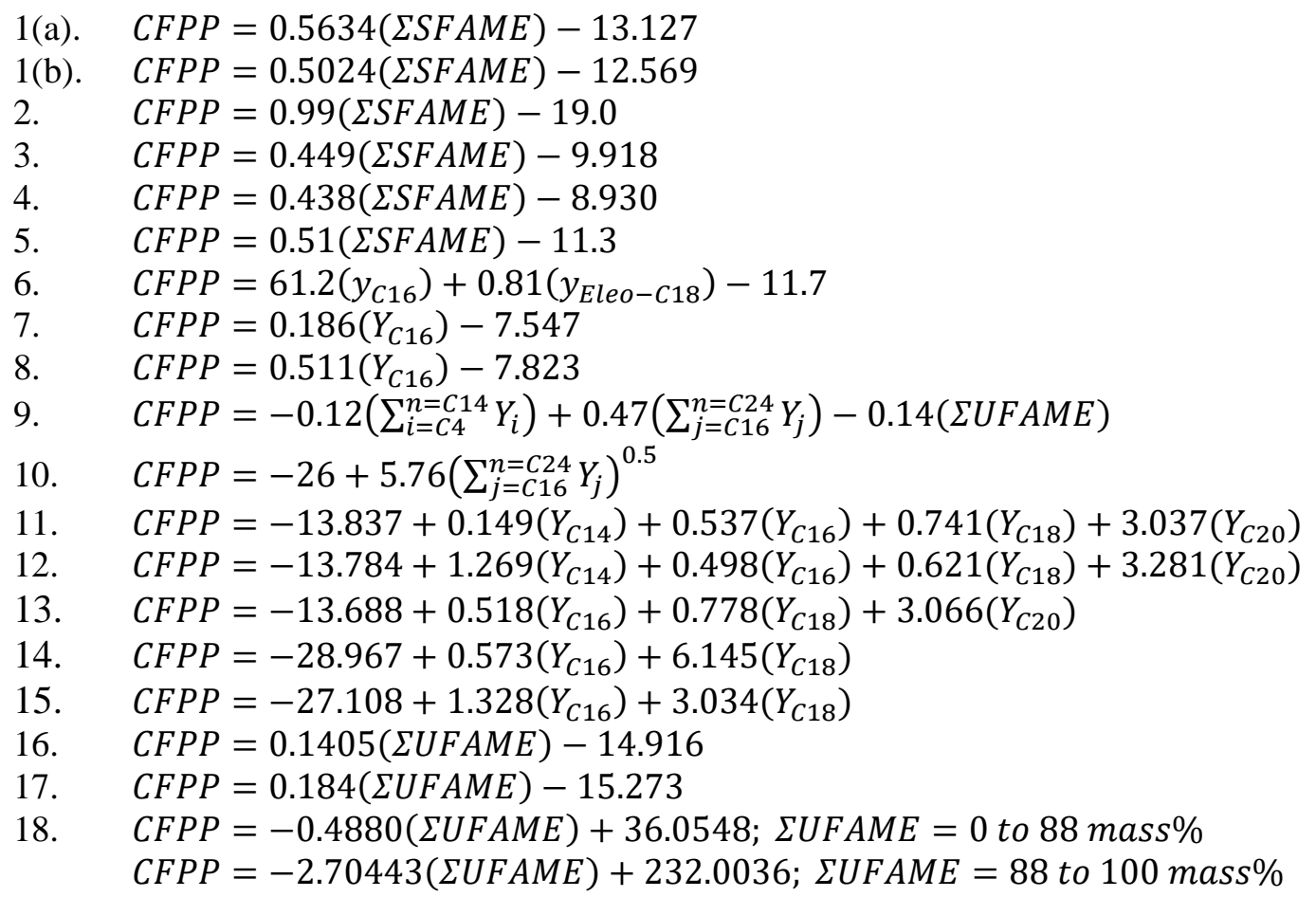


19. $\quad C F P P=-0.561(\Sigma U F A M E)+43.967$

20. $\quad C F P P=8.9243($ LCSF $[A]-$ Ramos $)-19.325$

$$
\operatorname{LCSF}[A]-\operatorname{Ramos}=\Sigma M P_{i}\left(y_{i}\right) ; i \geq C 18 \text { SFAME }
$$

21. $\quad C F P P=3.1417($ LCSF $[B]-$ Ramos $)-16.477$

$\operatorname{LCSF}[B]-\operatorname{Ramos}=0.1\left(y_{C 16}\right)+0.5\left(y_{C 18}\right)+1.0\left(y_{C 20}\right)+1.5\left(y_{C 22}\right)+2.0\left(y_{C 20}\right)$

22. $\quad C F P P=1.7566(L C S F-$ Wang $)-14.772$

$$
\text { LCSF-Wang }=\Sigma M P_{i}\left(y_{i}\right) ; i=C 14 \text { to C20 SFAME }
$$

23. $\quad C F P P(K)=18.019\left(N_{C}\right)-0.804(\Sigma U F A M E)$

24. $\quad C F P P=-0.221(I V)+22.031$

25. $C F P P=82.3069-17.831(L C)+50.9813(D U)+0.8584(L C)^{2}-5.5148(L C)(D U)+$ $11.949(D U)^{2}$

26. $\quad C F P P=90.5901+41.4424(v)-19.4541(L C)+37.2859(D U)$

$\underline{\text { Validation Testing of the Literature Models }}$

The tests were conducted using measured CFPP data $\left(\mathrm{CFPP}_{\text {meas }}\right)$ for the 28 biodiesel and admixture blends (Table 4 in the manuscript) paired with corresponding calculated values $\left(\mathrm{CFPP}_{\text {calc }}\right)$ obtained from application of the literature models in Table S1. Results from the 26 models are summarized in Table S2. Models 16 and 17 were reported by Jurac and Zlatar. ${ }^{3}$ These models were developed specifically for two separate rapeseed oil-FAME (RME)/used cooking oil-FAME (UCOME) admixtures. The paucity of data pairs for these models yielded inconclusive results with respect to scatter patterns in $\mathrm{CFPP}_{\text {meas }}$ versus $\mathrm{CFPP}_{\text {calc }}$ plots. These models were not advanced for comparison with the empirical models in the present study.

Model 15 (Yuan 5) was developed for FAME admixtures that contained low-erucic acid RME. ${ }^{1}$ This limited the number of data pairs to $n=17$ representing neat CaME (fatty acid concentration profile is similar to low-erucic acid RME) plus 12 admixtures with CaME. Comparisons for Model 24 (Moser 3) were conducted by first calculating the iodine value (IV) of the four neat FAME and 24 FAME admixtures using concentration data reported in Table 1 in the manuscript. Comparisons with Model 26 (Pinzi 2) were facilitated by calculating $v$ at $40{ }^{\circ} \mathrm{C}$ for the admixtures. These data were obtained by applying a modified Grunberg-Nissan equation as follows:

$$
\ln \left[v_{i}\right]=y_{1}\left(\ln \left[v_{1}\right]\right)+y_{2}\left(\ln \left[v_{2}\right]\right)
$$

where $v_{\text {mix }}=$ viscosity of the admixture, $y_{1}$ and $y_{2}$ are mass fractions of FAME 1 and FAME 2 and $v_{1}$ and $v_{2}$ are viscosities of FAME 1 and FAME 2 in the admixture. ${ }^{15}$ Measured $v$ values for the four neat FAME were taken from Table 5 in the manuscript to calculate the admixture viscosities and provide $n=28$ data pairs for comparison.

Table S2. Results from Validation Tests Performed on CFPP Models in Table S1. Slope, Intercept, $R^{\mathbf{2}}$ from Regression Analysis of Calculated $\left(\mathrm{CFPP}_{\text {calc }}\right)$ versus Measured $\left(\mathrm{CFPP}_{\text {meas }}\right)$ Data. ${ }^{a}$

\begin{tabular}{llccccccccc}
\hline No. & Name & $n$ & Slope & Intercept & $R^{2}$ & \multicolumn{2}{c}{ Scatter } & AAD & RMSD & Grade $^{b}$ \\
& & & & & & Pattern & Random & & & \\
\hline 1 & Echim & 28 & $1.02(0.05)$ & $-0.2(0.3)$ & 0.944 & Curve & No & 1.3 & 1.6 & A \\
2 & Gonzalez & 28 & $1.82(0.09)$ & $4.0(0.6)$ & 0.934 & Curve & No & 4.6 & 7.3 & F \\
3 & Jeong 1 & 28 & $0.83(0.04)$ & $0.5(0.3)$ & 0.934 & Curve & No & 1.3 & 1.8 & A \\
4 & Moser 1 & 28 & $0.81(0.04)$ & $1.2(0.3)$ & 0.934 & Curve & No & 1.6 & 2.2 & B \\
5 & Moser 2 & 28 & $0.94(0.05)$ & $0.5(0.3)$ & 0.934 & Curve & No & 1.2 & 1.7 & A
\end{tabular}




\begin{tabular}{llccccccccc}
6 & Chen & 28 & $1.06(0.06)$ & $-0.5(0.4)$ & 0.909 & Curve & No & 1.8 & 2.2 & $\mathrm{~B}$ \\
7 & Jeong 2 & 28 & $0.32(0.02)$ & $-4.1(0.1)$ & 0.909 & Curve $^{c}$ & No & 5.1 & 6.0 & $\mathrm{~F}$ \\
8 & Sarin 1 & 28 & $0.96(0.5)$ & $-2.9(0.3)$ & 0.918 & Curve & No & 3.0 & 3.4 & $\mathrm{~B}$ \\
9 & Serrano 1 & 28 & $1.1(0.06)$ & $0.0(0.3)$ & 0.936 & Curve & No & 1.5 & 1.9 & $\mathrm{~A}$ \\
10 & Serrano 2 & 28 & $1.1(0.03)$ & $0.7(0.2)$ & 0.975 & Curve & Yes? & 1.0 & 1.4 & $\mathrm{~A}$ \\
11 & Yuan 1 & 28 & $0.93(0.06)$ & $0.7(0.4)$ & 0.904 & Curve & Yes? & 1.6 & 2.0 & $\mathrm{~A}$ \\
12 & Yuan 2 & 28 & $0.90(0.06)$ & $-0.1(0.4)$ & 0.888 & Curve & Yes? & 1.7 & 4.0 & $\mathrm{~B}$ \\
13 & Yuan 3 & 28 & $0.90(0.06)$ & $0.6(0.4)$ & 0.904 & Curve & Yes? & 1.6 & 2.0 & $\mathrm{~A}$ \\
14 & Yuan 4 & 28 & $1.4(0.2)$ & $7(1)$ & 0.711 & Loop $^{c}$ & No & 7.8 & 9.6 & $\mathrm{~F}$ \\
15 & Yuan 5 & 17 & $2.2(0.1)$ & $8.1(0.8)$ & 0.966 & Linear $^{c}$ & Yes? & 5.3 & 8.4 & $\mathrm{~F}$ \\
16 & Jurac 1 & 4 & $1.1(0.2)$ & $-3(1)$ & 0.880 & NC & No & 3.1 & 3.3 & $\mathrm{~B}$ \\
17 & Jurac 2 & 4 & $1.4(0.3)$ & $1(2)$ & 0.880 & NC & No & 2.0 & 2.2 & $\mathrm{~B}$ \\
18 & Park & 28 & $1.12(0.05)$ & $-2.3(0.3)$ & 0.949 & Curve & No & 2.5 & 2.9 & $\mathrm{~B}$ \\
19 & Sarin 2 & 28 & $1.03(0.05)$ & $0.9(0.3)$ & 0.934 & Curve & No & 1.3 & 2.0 & $\mathrm{~A}$ \\
20 & Ramos 1 & 28 & $0.2(0.1)$ & $-3.0(0.8)$ & 0.075 & Loop & No & 5.6 & 7.1 & $\mathrm{~F}$ \\
21 & Ramos 2 & 28 & $0.64(0.05)$ & $-2.7(0.3)$ & 0.838 & Loop & No & 3.1 & 4.0 & $\mathrm{~B}$ \\
22 & Wang & 28 & $0.96(0.05)$ & $-2.0(0.3)$ & 0.938 & Curve & No & 2.2 & 2.5 & $\mathrm{~B}$ \\
23 & Su & 28 & $0.84(0.04)$ & $1.3(0.3)$ & 0.939 & Curve $^{c}$ & No & 1.6 & 2.1 & $\mathrm{~B}$ \\
24 & Moser 3 & 28 & $0.64(0.09)$ & $-0.1(0.6)$ & 0.627 & Curve & Yes? & 2.9 & 3.8 & $\mathrm{~B}$ \\
25 & Pinzi 1 & 28 & $0.44(0.08)$ & $-2.3(0.5)$ & 0.514 & Curve $^{c}$ & Yes? & 4.3 & 5.0 & $\mathrm{~F}$ \\
26 & Pinzi 2 & 28 & $-0.10(0.02)$ & $-28.2(0.3)$ & 0.106 & Linear $^{c}$ & Yes & 28 & 29 & $\mathrm{~F}$ \\
\hline
\end{tabular}

Numbers in parentheses are SD from $n=3$ replicate analyses.

$a_{n}=$ Total number of data pairs compared; $\mathrm{AAD}=$ average absolute deviation $\left(\triangle \mathrm{CFPP}=\mathrm{CFPP}_{\text {meas }}-\mathrm{CFPP}_{\text {calc }}\right)$; RMSD = root-mean-square deviation; $\mathrm{NC}=$ inconclusive. See Table $\mathrm{S} 1$ for abbreviations.

${ }^{b}$ Grades: $\mathrm{A}=\mathrm{AAD}$ and $\mathrm{RMSD} \leq 2.0 ; \mathrm{B}=\mathrm{AAD}$ or $\mathrm{RMSD}=2.0-4.0 ; \mathrm{F}=\mathrm{AAD}$ or $\mathrm{RMSD}>4.0$.

${ }^{c}$ Data pattern is not coincidental to the $1: 1$ line $\left(\mathrm{CFPP}_{\text {meas }}=\mathrm{CFPP}_{\text {calc }}\right)$.

The validation tests were based on results from linear regression analysis of CFPP meas versus CFPP $_{\text {calc }}$ data for each literature model. None of the models passed this test with respect to slope $\sim 1$, intercept $\sim 0$ and a linear correlation $\left(R^{2} \geq 0.98\right)$ from regression analysis. Model 10 (Serrano 2) was close to passing with respect to slope $=1.09$, intercept $=0.0$ and $R^{2}=0.9749$. Five models $(1,5,6,9$ and 12) yielded slope $=1 \pm 0.1$ and intercept $=0 \pm 0.5$ coupled with nearly linear behavior $\left(R^{2}=0.888-0.944\right)$. Results for 19 models were nearly coincident with a 1:1 line where $\mathrm{CFPP}_{\text {calc }}=\mathrm{CFPP}_{\text {meas }}$. However, these models had non-random scatter patterns that were curvilinear in shape. Models 10-13 and 24 had slight curvature and nearly random scatter patterns.

The deviation results $(\mathrm{AAD}=$ average absolute deviation and $\mathrm{RMSD}=$ root-meansquared deviation) were graded on the following scale: 1 ) if both AAD and RMSD were $\leq 2.0$, the assigned grade was ' $\mathrm{A}$ '; 2 ) if either $\mathrm{AAD}$ or RMSD were in the range 2.0-4.0, the grade was ' $\mathrm{B}$ '; and 3 ) if either AAD or RMSD $>4.0$, the grade was ' $F$ '. The total assigned grades were 8 A's, 11 B's and 7 F's.

The two models (Ramos 1 and Wang) correlated with LCSF[A]-Ramos and LCSF-Wang as independent variables were advanced for comparison with the new models developed in the present work. These factors were calculated by taking a weighted average of SFAME mass concentrations using the MP of the SFAME as weighing factors. ${ }^{11,12}$ It was noted earlier that while the LCSF[A]-Ramos accounted for only the presence of C18+ SFAME in the mixtures, the LCSF-Wang accounted for the presence of all C14-C20 SFAME. One of the new models introduces another modified LCSF ( LCSF $_{\text {mod }}$ ) where only C16+ SFAME are accounted for in a correlation for predicting the CFPP of FAME mixtures. Model 23 (Su) was also compared with the new models in the manuscript because it was partially correlated to the molar average chain 
length of FAME $\left(N_{\mathrm{C}}\right)$ in the mixtures. The MP of FAME species were shown to be correlated to their chain-length. ${ }^{16}$ Model 23 yielded smaller deviations and was close to receiving an A-grade.

The seven models that failed the validation tests had the highest combined AAD+RMSD and were collectively the only models that did not demonstrate data patterns coincidental to the 1:1 correlation line $\left(\mathrm{CFPP}_{\text {calc }}=\mathrm{CFPP}_{\text {meas }}\right)$. Model 25 (Pinzi 1) was similar to Model $23(\mathrm{Su})$ because its independent variables, LC (mass-average chain length) and DU (degree of unsaturation), were analogous to $N_{\mathrm{C}}$ and $\Sigma$ UFAME in the latter model. It is possible that calculating the parameters on a mass basis for Model 25 contributed to its poor validation performance. The worst performing model was Model 26 (Pinzi 2). This model was correlated with respect to LC, DU and $v$ and yielded the highest combined AAD+RMSD. Model 14 (Yuan 4) was derived using results for admixtures containing large concentrations of methyl decanoate (MeC10) and methyl dodecanoate (MeC12). None of the four FAME studied herein contained detectable concentrations of these SFAME. Model 15 (Yuan 5) was correlated for admixtures with low-erucic acid RME and had the largest range in absolute deviation ( $A D=0.1$ to 24$)$. Lastly, it was noted that Model 24 (Moser 3) was the only correlation based on the IV of the admixtures. This model yielded a B-grade despite having low slope (0.64) and $R^{2}(0.627)$.

A conclusive assessment of the 26 literature models yielded 10 models to be advanced for direct comparison with results for the new CFPP models developed in the present work. These models were selected based on validation results where slope $=1 \pm 0.2$, intercept $=0 \pm 1$ and $R^{2}$ $>0.9$ was exhibited. Ranking the 10 models in ascending order of combined AAD+RMSD yielded: Serrano 2 (model 10) < Echim $(1)=$ Moser 2 (5) < Jeong 1 (3) < Sarin 2 (19) < Serrano $1(9)<$ Yuan $3(13)=$ Yuan $1(11)<$ Chen (6) < Yuan 2 (12). Three additional models, 20, 22 and 23 were advanced for comparison with the new models. Validation test results for Model 20 (Ramos 1) yielded low slope and intercept coefficients and $R^{2}>0.2$. Models 22 and 23 failed validation owing to intercept coefficients being outside the range $0 \pm 1$. As noted earlier, these models are compared with the new models based on similarities in how they were developed.

\section{Melting Properties of FAME}

Table S3. Melting Properties of Pure FAME. ${ }^{a}$

\begin{tabular}{|c|c|c|c|c|}
\hline \multirow[t]{2}{*}{ FAME } & \multirow{2}{*}{$\begin{array}{l}\mathrm{Mol} \mathrm{Wt} \\
\mathrm{g} \mathrm{mol}^{-1}\end{array}$} & \multicolumn{2}{|c|}{$\mathrm{MP}^{b}$} & \multirow{2}{*}{$\begin{array}{c}\Delta H_{\text {fus }}{ }^{c} \\
\mathrm{~kJ} \mathrm{~mol}^{-1}\end{array}$} \\
\hline & & ${ }^{\circ} \mathrm{C}$ & K & \\
\hline $\mathrm{MeC14}$ & 242.40 & 18.99 & 292.14 & 52.01 \\
\hline MeC16 & 270.47 & 29.56 & 302.71 & 60.04 \\
\hline MeC16:1 & 268.43 & -34.1 & 239.1 & $24.3^{d}$ \\
\hline $\mathrm{MeC} 18$ & 298.50 & 38.69 & 311.84 & 66.35 \\
\hline MeC18:1 & 296.49 & -20.71 & 252.44 & 38.7 \\
\hline MeC18:2 & 297.47 & -43.90 & 229.25 & 30.29 \\
\hline MeC18:3 & 292.46 & -57 & 216 & $21^{d}$ \\
\hline $\mathrm{MeC} 20$ & 326.56 & 46.33 & 319.48 & 78.79 \\
\hline MeC20:1 & 324.54 & -9 & 264.15 & 57.8 \\
\hline
\end{tabular}

${ }^{a} \mathrm{Mol} \mathrm{Wt}=$ molecular weight; $\mathrm{MP}=$ melting point; $\Delta H_{\text {fus }}=$ enthalpy of fusion; $\mathrm{MeC} 14=$ methyl myristate; $\mathrm{MeC} 16=$ methyl palmitate; MeC16:1 = methyl palmitoleate; MeC18 = methyl stearate; MeC18:1 = methyl oleate; MeC18:2 = methyl linoleate; Me C18:3 = methyl linolenate; $\mathrm{MeC} 20$ = methyl arachidate; MeC20:1 = methyl eiconsenoate. See Table S1 for abbreviations.

${ }^{b}$ Sources: References 17-22.

'Sources: References 18-21.

${ }^{d}$ Estimated from unpublished differential scanning calorimetry (DSC) results. 


\section{Example Calculation of $T_{\text {SLE }}$ of Neat (Unblended) Yellow Grease-FAME (YGME)}

Presented in Table $\mathrm{S} 4$ are mole fraction $\left(x_{\mathrm{i}}\right)$ and equilibrium crystallization temperatures $\left(T_{\mathrm{f}}\right)$ for each FAME species ' $i$ ' in neat yellow grease-FAME (YGME) biodiesel. The $x_{\mathrm{i}}$ data were calculated from results from analysis of FAME compositions in Table 1 in the manuscript. The $T_{\mathrm{f}}$ values were calculated from eq 1 in the manuscript using melting properties summarized in Table S3. For YGME, MeC18 had the highest calculated $T_{\mathrm{f}}$ value was $8.44^{\circ} \mathrm{C}$ for $\mathrm{MeC} 18$. Hence, this was taken as the $T_{\mathrm{SLE}}$ value for neat YGME as highlighted in the last two columns of the table. Note that the $T_{\mathrm{f}}$ value for $\mathrm{MeC} 16$ was only $1.30{ }^{\circ} \mathrm{C}$ lower than the same value for $\mathrm{MeC} 18$ (proximity of some $T_{\mathrm{f}}$ values is discussed in the manuscript).

Table S4. Determining the Solid-Liquid Equilibrium Transition Temperature ( $\left.T_{\text {SLE }}\right)$ and Controlling FAME of Neat Yellow Grease-FAME (YGME). ${ }^{a}$

\begin{tabular}{lcccccc}
\hline \multicolumn{1}{c}{ FAME } & $x_{\mathrm{i}}$ & $\mathrm{K}$ & $T_{\mathrm{f}}$ & & \multicolumn{2}{c}{$T_{\text {SLE }}$} \\
\cline { 5 - 7 } MeC16 & & ${ }^{\circ} \mathrm{C}$ & & ${ }^{\circ} \mathrm{C}$ & FAME \\
MeC16:1 & 0.1483 & 280.29 & 7.14 & & \\
MeC18 & 0.0096 & 173.18 & -99.97 & & \\
MeC18:1 & 0.0640 & 281.59 & 8.44 & 8.44 & \\
MeC18:2 & 0.400 & 240.47 & -32.68 & & \\
MeC18:3 & 0.337 & 214.56 & -58.59 & & \\
MeC20 & 0.0348 & 167.47 & -105.68 & & \\
\hline
\end{tabular}

${ }^{a} x_{\mathrm{i}}=$ Mole fraction of FAME species 'i'; $T_{\mathrm{f}}=$ transition temperature of FAME species 'i' calculated from eq 1 in manuscript using melting properties in Table S3. See Tables S1 and S3 for abbreviations.

\section{$\underline{\text { Graphical Results from Validation Tests on Four Selected Literature Models }}$}

Below are results from validation tests performed on Models 1 (Echim), 5 (Moser 2), 20 (Ramos 1) and $23(\mathrm{Su})$ showing the data trends and scatter patterns from plots of CFPP $\mathrm{Calc}_{\text {versus }}$ $\mathrm{CFPP}_{\text {meas. }}$ The last two models are discussed in comparison with results for the new CFPP models in the manuscript. Measured CFPP data were from Table 4 in the manuscript.

Model 1 (Echim)
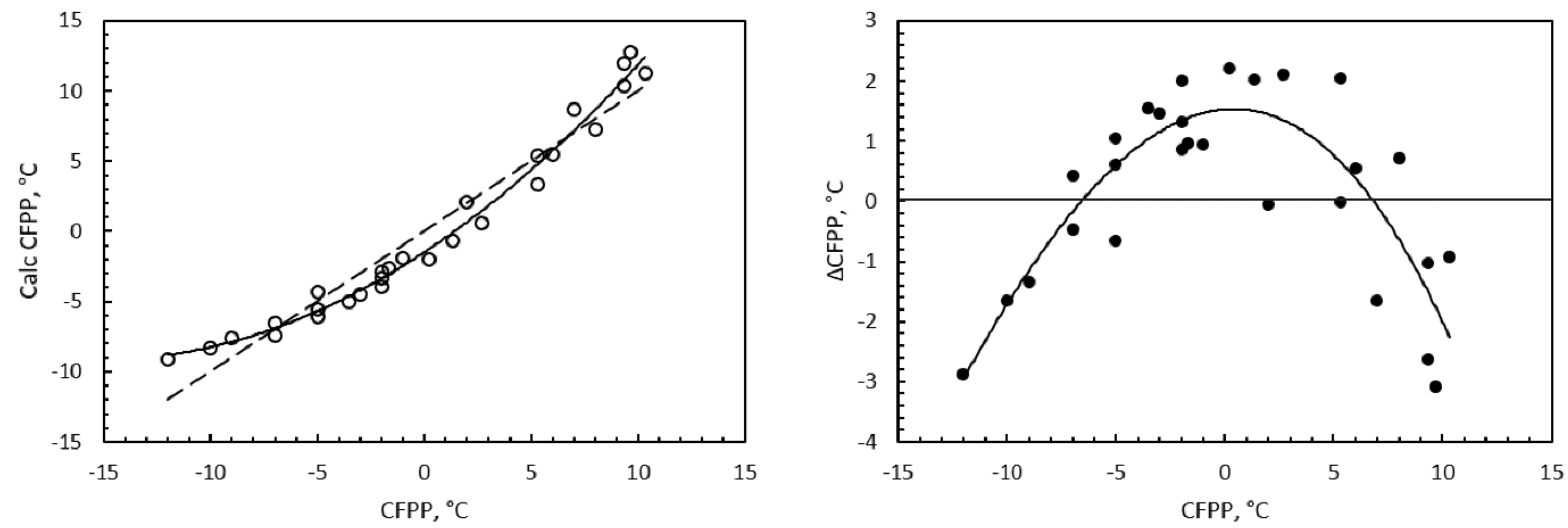

Figure S1. Validation test results for Model 1 (Echim). Left: measured versus calculated CFPP (CFPP meas $_{\text {versus }}$ $\left.\mathrm{CFPP}_{\text {calc }}\right)$ data. Right: residuals $\left(\triangle \mathrm{CFPP}=\mathrm{CFPP}_{\text {meas }}-\mathrm{CFPP}_{\text {calc }}\right)$. Solid lines $=$ trendlines; dashed line $=1: 1$ correlation $\left(\mathrm{CFPP}_{\text {calc }}=\mathrm{CFPP}_{\text {meas }}\right)$. 


\section{Model 5 (Moser 2)}
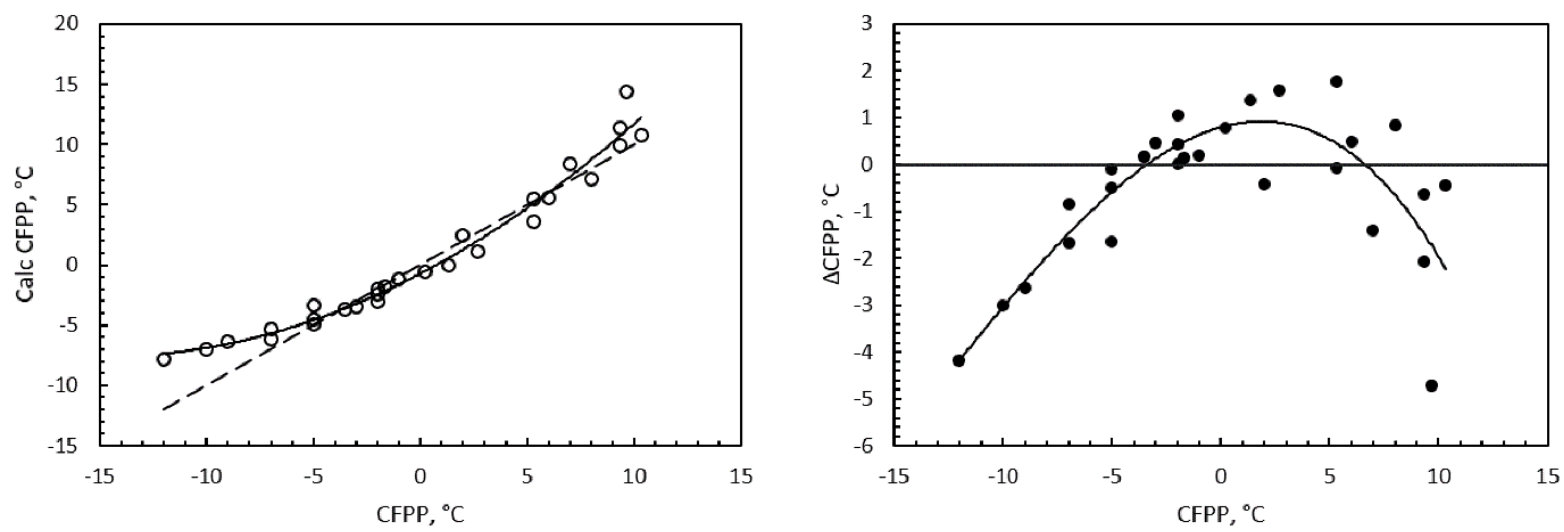

Figure S2. Validation tests results for Model 5 (Moser 2). Left: $\mathrm{CFPP}_{\text {meas }}$ versus $\mathrm{CFPP}_{\text {calc }}$ data. Right: residuals. Solid lines $=$ trendlines; dashed line $=1: 1$ correlation. See Figure $\mathrm{S} 1$ for abbreviations and definitions.

\section{Model 20 (Ramos 1)}
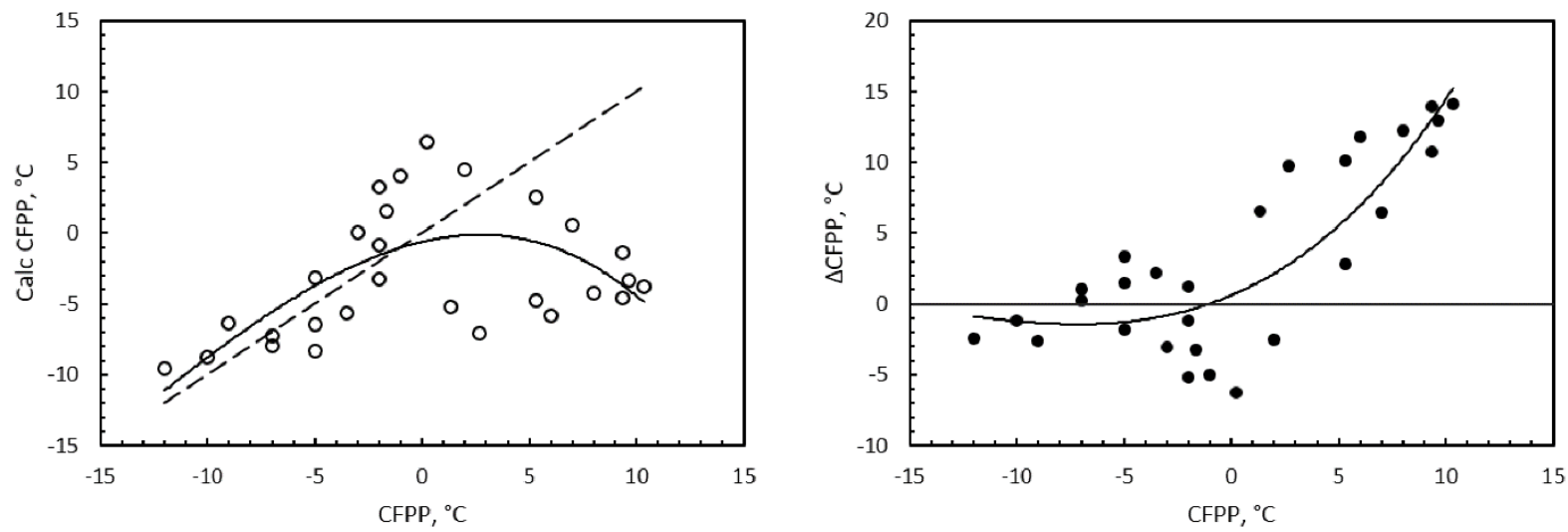

Figure S3. Validation test results for Model 20 (Ramos 1). Left: $\mathrm{CFPP}_{\text {calc }}$ versus $\mathrm{CFPP}_{\text {meas }}$ data. Right: residuals. Solid lines $=$ trendlines; dashed line $=1: 1$ correlation. See Figure $\mathrm{S} 1$ for abbreviations and definitions. 
Model 23 (Su)
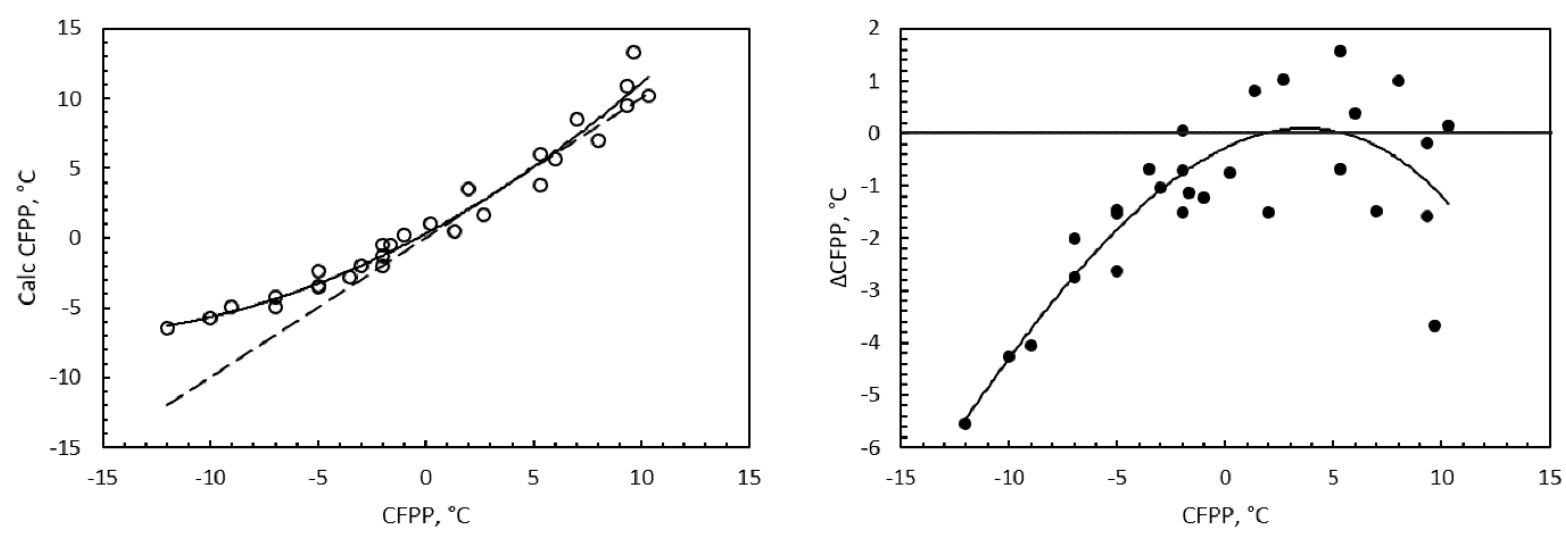

Figure S4. Validation test results for Model 23 (Su). Left: $\mathrm{CFPP}_{\text {meas }}$ versus $\mathrm{CFPP}_{\text {calc }}$ data. Top: residuals. Solid lines $=$ trendlines; dashed line $=1: 1$ correlation. See Figure S1 for abbreviations and definitions.

$\underline{\text { References }}$

(1) Yuan, M.-H.; Chen, Y.-H.; Chen, J.-H.; Luo, Y.-M. Fuel 2017, 195, 59-68.

(2) Serrano, M.; Oliveros R.; Sánchez, M.; Moraschini, A.; Martínez, M.; Aracil, J. Energy 2014, 65, 109-115.

(3) Jurac, Z.; Zlatar, V. Fuel Process Technol. 2013, 106, 108-113.

(4) Echim, C.; Maes, J.; De Greyt, W. Fuel 2012, 93, 642-648.

(5) Chen, Y.-H.; Chen, J.-H.; Chang, C.-Y.; Chang, C.-C. Bioresour. Technol. 2010, 101, 9521-9526.

(6) Sarin, A.; Arora, R.; Singh, N. P.; Sarin, R.; Malhotra, R. K.; Sarin, S. Energy Fuels 2010, 24, 1996-2001.

(7) Jeong, G.-T.; Park, J.-H.; Park, S.-H.; Park, D.-H. Biotechnol. Bioprocess Eng. 2008, 13, 505-510.

(8) Moser, B. R. Energy Fuels 2008, 22, 4301-4306.

(9) Park, J.-Y.; Kim, D.-K.; Lee, J.-P.; Park, S.-C.; Kim, Y.-J.; Lee, J.-S. Bioresour. Technol. 2008, 99, 1196-1203.

(10) González Gómez, M. E.; Howard-Hildige, R.; Leahy, J. J.; Rice, B. Fuel 2002, 81, 3339. 404.

(11) Wang, L.-B.; Yu, H.-Y.; He, X.-H.; Liu, R.-Y. J. Fuel Chem. Technol. 2012, 40, 397-

(12) Ramos, M. J.; Fernández, C. M.; Casas, A.; Rodríguez, L.; Pérez, A. Bioresour. Technol. 2009, 100, 261-268.

(13) Su, Y.-C.; Liu, Y. A.; Tovar, C. A. D.; Gani, R. Ind. Eng. Chem. Res. 2011, 50, 68096836.

(14) Pinzi, S.; Leiva, D.; Arzamendi, G.; Gandia, L. M.; Dorado, M. P. Bioresour. Technol. 2011, 102, 7280-7288.

(15) Knothe, G.; Steidley, K. R. Fuel 2011, 90, 3217-3224.

(16) Dunn, R. O. Trans. ASABE 2012, 55, 637-646.

(17) Knothe, G.; Dunn, R. O. J. Am. Oil Chem. Soc. 2009, 86, 843-856.

(18) Knothe, G. Energy Fuels 2008, 22, 1358-1364. [*NIST database] 
(19) Foon, C. S.; Liang, Y. C.; Dian, N, L, H, M,; May, C. Y.; Hock, C. C.; Ngan, M. A. Am. J. Appl. Sci. 2006, 3, 1859-1863.

(20) van Bommel, M. J.; Oonk, H. A. J.; van Miltenburg, J. C. J. Chem. Eng. Data 2004, 49, 1036-1042. [*NIST database]

(21) Chang, S. P.; Rothfus, J. A. J. Am. Oil Chem. Soc. 1996, 73, 403-410.

(22) Rakoff, H.; Emken, E. A. Chem. Phys. Lipids 1982, 31, 215-225. 